\title{
Ultracentrifugal Characterization of Poly(ethylene terephthalate) in Dilute Solutions
}

\author{
Seiji OHoya, $^{\dagger}$ Taiichi Hasegawa, Kyoji TsubakiYama, and Togoro Matsuo \\ Faculty of Engineering, Fukui University, 3-9-1 Bunkyo, \\ Fukui 910-8507, Japan
}

(Received May 29, 2000; Accepted October 31, 2000)

\begin{abstract}
The well-fractionated poly(ethylene terephthalate) (PET) samples ranging in weight average molecular weight $M_{\mathrm{W}}$ from 0.9 to $16 \times 10^{4}$ have been studied by sedimentation velocity and equilibrium, and viscometry in hexafluoroisopropanol (HFIP) and $m$-cresol at $30^{\circ} \mathrm{C}$. The second virial coefficient $A_{2}$ determined in HFIP by the sedimentation equilibrium method is found to have high dependence on $M_{\mathrm{W}}$ expected for the helical wormlike chains in very good solvents. The constant $\Phi^{1 / 3} P^{-1}$ in the Mandelkern-Flory equation is $2.54 \times 10^{6}$ for PET in HFIP and $2.57 \times 10^{6}$ in $m$ cresol, being in excellent agreement with that reported for several polymer-solvent systems. The dependences of sedimentation coefficient $s_{0}$ on $M_{\mathrm{W}}$ agree with also those expected for good solvents. The Mark-Houwink-Sakurada relations established with HFIP and $m$-cresol as the solvents are

$$
\begin{aligned}
& {[\eta]=2.95 \times 10^{-4} M_{\mathrm{W}}{ }^{0.72} \text { in HFIP at } 30^{\circ} \mathrm{C}\left(3.1 \times 10^{4}<M_{\mathrm{W}}\right)} \\
& {[\eta]=4.97 \times 10^{-3} M_{\mathrm{W}}{ }^{0.48} \text { in HFIP at } 30^{\circ} \mathrm{C}\left(3.1 \times 10^{4}>M_{\mathrm{W}}\right)} \\
& {[\eta]=4.04 \times 10^{-4} M_{\mathrm{W}}{ }^{0.68} \text { in } m \text {-cresol at } 30^{\circ} \mathrm{C}\left(2.4 \times 10^{4}<M_{\mathrm{W}}\right)}
\end{aligned}
$$

The values of steric factor $\sigma$ estimated from the unperturbed chain dimensions range from 1.3 to 1.5 , irrespective of the solvent nature, and such small $\sigma$ values suggest that the extent of steric hindrance to the internal rotation of PET chain is significantly low.
\end{abstract}

KEY WORDS Poly(ethylene terephthalate) / Hexafluoroisopropanol / $m$-Cresol / Sedimentation Experiment / Mark-Houwink-Sakurada Relationship / Unperturbed Chain Dimension /

In spite of an important polymer that has been widely used for a variety of industrial purposes, poly(ethylene terephthalate) (PET) is not still completely disclosed about its molecular characteristics and solution properties. $^{1-8}$ For example, there is significant disagreement among the constants of $K^{\prime}$ and $a$ of the Mark-HouwinkSakurada (MHS) relationship, eq 1, compiled for several PET-solvent systems in "Polymer Handbook"; ${ }^{9}$

$$
[\eta]=K^{\prime} M^{\mathrm{a}}
$$

where $[\eta]$ is the intrinsic viscosity and $M$ is the molecular weight. The reasons for this are that PET is soluble only in a limitted number of rather peculiar and dangerous solvents, such as trifluoroacetic acid (TFA) and $o$ chlorophenol (o-CP), and that the establishments of most MHS equations are based on the number average molecular weight $M_{\mathrm{n}}$ using the unfractionated samples. The reliable unperturbed chain dimensions, therefore, have not been determined in terms of the MHS relation proposed.

The molecular weight and its distribution for several commercial PET samples have recently been measured in hexafluoroisopropanol (HFIP) by Naoki et al. ${ }^{10}$ with light scattering and gel permeation chromatography (GPC). On the other hand, a series of preliminary experiments ${ }^{11,12}$ revealed that HFIP is an easy handling and very good solvent for PET. In this work, we direct our efforts toward the establishment of rigorous MHS relations for PET in HFIP and $m$-cresol. For this purpose, the polymer was first fractionated by a column elution method $^{13}$ and then the fractions obtained were characterized by sedimentation experiments and viscometry. The results for $m$-cresol solutions were compared with

${ }^{\dagger}$ To whom all correspondence should be addressed. those obtained in $m$-cresol by Meyerhoff and Shimotsuma. ${ }^{2}$ Sedimentation equilibrium offers the weight average molecular weight $M_{\mathrm{W}}$ and requires least correction for polydispersity. HFIP is available with high refractive index increment $\mathrm{d} n / \mathrm{d} c$ allowing a measurement at low polymer concentraion and providing good precision in $M_{\mathrm{W}}$. The viscosity-molecular weight relations thus determined are available for the reliable evaluation of unperturbed chain dimensions $\left(\left\langle r^{2}\right\rangle_{0} / M\right)^{1 / 2}$ from which the chain conformational parameter $\sigma$ is derived by the Stockmayer-Fixman method. ${ }^{14}$

According to rather old-fashioned theory of the polymer solutions, ${ }^{15}$ the dependences of a part of the molecular parameters obtained on molecular weight are discussed briefly. Taking into account the chain stiffness based on the helical wormlike chain, on the other hand, Yamakawa ${ }^{16}$ has been developed recently the so-called quasi-two-parameter scheme. In his new theory, it is assumed that $\alpha$ is a function only of $\tilde{z}$, that is,

with

$$
\begin{aligned}
& \alpha=\alpha(\tilde{z}) \\
& \tilde{z}=(3 / 4) K(L) z
\end{aligned}
$$

where $K(L)$ is the kernel and $L$ is the total contour length. By replacing the excluded volume parameter $z$ in a two-parameter expression for $\alpha(z)$ by $\bar{z}$, new equations for the end-distance expansion factor $\alpha_{\mathrm{R}}$ and the gyration-radius expansion factor $\alpha_{\mathrm{S}}$ may be derived as,

$$
\begin{aligned}
& \alpha_{\mathrm{R}}^{2}=1+1.333 \tilde{z}-2.075 \bar{z}^{2}+\cdot \cdot \cdot \\
& \alpha_{\mathrm{S}}{ }^{2}=1+1.276 \bar{z}-2.220 \bar{z}^{2}+. \cdot .
\end{aligned}
$$

where $\bar{z}$ refers to the intramolecular scaled excluded volume parameter. It has been described that $\bar{z}$ slowly approaches its coil-limiting value $z$ as $L$ is increased. There has been seen good agreement between quasi-two- 
parameter theoretical and experimental values. Then, with the aid of several recent theories ${ }^{17-20}$ including the Yamakawa's one ${ }^{16}$ the other consideration of the results are made.

\section{EXPERIMENTAL}

\section{Samples}

A commercially available PET for tire cord supplied by Unitika Co. was dissolved in 1/1 mixture (by volume) of phenol/tetrachloroethane and reprecipitated by pouring the solution into methanol. Fractionation of PET was carried out by a column elution method. ${ }^{13}$ In the larger column, $3 \mathrm{~g}$ of the polymer was fractionated into fourteen fractions (run 1), using glass beads as a polymer support material and stepwise mixtures of $o-\mathrm{CP} / n$ heptane as eluents. The procedure simillar to that just described was applied to the smaller column to fractionate $1 \mathrm{~g}$ of the polymer into six fractions (run 2-4). Thirteen fractions (sample code: $1 \mathrm{~A}-1 \mathrm{~L}, 4 \mathrm{~A}$, and $4 \mathrm{E}$ ) ranging in molecular weight $\left(M_{\mathrm{Pst}}\right)$ by GPC from 1.3 to $20.1 \times$ $10^{4}$ and an unfractionated polymer (UF, $M_{\mathrm{Pst}}=7.0 \times 10^{4}$ ) were chosen as the samples in this work, here $M_{\text {Pst }}$ stands for the molecular weight reduced to a polystyrene basis.

\section{Ultracentrifugation}

The sedimentation experiments for PET in HFIP and in $m$-cresol were carried out with a Spinco Model $\mathrm{E}$ analytical ultracentrifuge at $30^{\circ} \mathrm{C}$, using schlieren optics for the sedimentation velocity method and Rayleigh interference optics for the sedimentation equilibrium method. Centerpieces used were a Kel-F 12-mm single sector cell for sedimentation velocity and an aluminium 12-mm double sector one for sedimentation equilibrium, and in the latter, $0.08 \mathrm{~mL}$ of sample solution was injected with a microsyringe into the right hand sector to adjust the liquid column to $1.5 \mathrm{~mm}$. The rotor speed was chosen as $5-6 \times 10^{4} \mathrm{rpm}$ for sedimentation velocity and $9 \times 10^{3}-3$ $\times 10^{4} \mathrm{rpm}$ for sedimentation equilibrium, respectively, depending on molecular weight of samples. Schlieren patterns and interference fringe patterns were read on a Nikon Profile Projector V-10, and the fringe profiles were converted to concentration profiles using the specific refractive index increment $\mathrm{d} n / \mathrm{d} c$; the values of $\mathrm{d} n /$ $\mathrm{d} c$ for PET measured at $546 \mathrm{~nm}$ and at $30^{\circ} \mathrm{C}$ by the use of a modified Debye type differential refractometer ${ }^{21}$ were $0.262 \mathrm{~cm}^{3} \mathrm{~g}^{-1}$ in HFIP and $0.040 \mathrm{~cm}^{3} \mathrm{~g}^{-1}$ in $\mathrm{m}$-cresol. ${ }^{12}$ The partial specific volumes $\bar{v}$ of PET were determined by making use of a Digital Density Meter SS (Shibayama), being $0.691 \mathrm{~cm}^{3} \mathrm{~g}^{-1}$ in HFIP and $0.725 \mathrm{~cm}^{3}$ $\mathrm{g}^{-1}$ in $m$-cresol, ${ }^{12}$ and hence, together with solvent density $\rho_{0}$, giving the buoyancy factors $\left(1-\bar{v} \rho_{0}\right)$ of -0.099 and 0.256 , respectively.

The sedimentation coefficient $s$ in $\mathrm{S}\left(\equiv 10^{-13} \mathrm{sec}\right)$ was determined using both the peak method and the Baldwin method ${ }^{22}$ (eq 5) for a part of sample, and the values of $s$ with both methods agreed within the error of $1 \%$. The subsequent determinations of the sedimentation coefficient, therefore, were carried out according to the peak method (eq 6),

$$
\begin{gathered}
s=-\frac{1}{2 \omega^{2}} \cdot \frac{\mathrm{d} \ln c_{\mathrm{P}}}{\mathrm{d} t} \\
s=\frac{1}{\omega^{2}} \cdot \frac{\mathrm{d} \ln r_{\mathrm{m}}}{\mathrm{d} t}
\end{gathered}
$$

where $c_{\mathrm{P}}$ is the mass concentration of polymer in the plateau region, $r_{\mathrm{m}}$ distance from the center of rotation to the peak position, $\omega(=\operatorname{rpm} \times 2 \pi / 60)$ angular revolution velocity of the rotor, and $t$ time of centrifugation. The $s$ values were measured at the different initial mass concentrations of polymer $c_{0}$ and their reciprocals were extrapolated to $c_{0}=0$ by the least squares method of the following emperical equation,

$$
s^{-1}=s_{0}^{-1}+s_{0}^{-1} k_{\mathrm{S}} c_{0}
$$

in order to determine the limiting sedimentation coefficient $s_{0}$, where $k_{\mathrm{S}}$ is a constant independent of $c_{0}$.

The values of weight- and z-average molecular weights, $M_{\mathrm{W}}$ and $M_{\mathrm{Z}}$, and the second virial coefficient $A_{2}$ were determined by the least mean square method using the following equations, ${ }^{22,23}$

$$
\begin{gathered}
M_{\mathrm{W}, \mathrm{app}}^{-1}=M_{\mathrm{W}}^{-1}+2 A_{2} \bar{c}+\cdots \\
Q=\left(M_{\mathrm{W}} / M_{\mathrm{Z}}\right)\left(1+2 A_{2} M_{\mathrm{W}} \bar{c}+\cdot \cdot \cdot\right)
\end{gathered}
$$

with

$$
\begin{gathered}
M_{\mathrm{W}, \mathrm{app}}=\frac{2 R T\left(c_{\mathrm{b}}-c_{\mathrm{a}}\right)}{\left[c_{0} \omega^{2}\left(r_{\mathrm{b}}{ }^{2}-r_{\mathrm{a}}{ }^{2}\right)\left(1-\bar{v} \rho_{0}\right)\right]} \\
Q=\frac{\left(c_{\mathrm{b}}-c_{\mathrm{a}}\right)^{2}}{c_{0}\left(r_{\mathrm{b}}{ }^{2}-r_{\mathrm{a}}{ }^{2}\right)\left[\left(\partial c / \partial r^{2}\right)_{r=r_{\mathrm{b}}}-\left(\partial c / \partial r^{2}\right)_{r=r_{\mathrm{a}}}\right]} \\
\bar{c}=\left(c_{\mathrm{a}}+c_{\mathrm{b}}\right) / 2
\end{gathered}
$$

where $r_{\mathrm{a}}$ and $r_{\mathrm{b}}$ stand for the radial distances from the center of rotation to the meniscus and the cell bottom, respectively, and $c_{\mathrm{a}}$ and $c_{\mathrm{b}}$ refer to the equilibrium mass concentration of polymer at $r_{\mathrm{a}}$ and $r_{\mathrm{b}}$, respectively; $R$ the gas constant, and $T$ the absolute temperature.

\section{Viscometry}

Solution Viscosities of the PET fractions in HFIP and $m$-cresol were measured at $30^{\circ} \mathrm{C}$ using an Ubbelohde type capillary viscometer. The Huggins plot and the Fuoss-Mead plot were extrapolated to the common intercept to determine $[\eta]$.

\section{RESULTS AND DISCUSSION}

\section{On the Sedimentation Data}

In Figures 1 and 2 are shown the sedimentation equilibrium data in HFIP, where $M_{\mathrm{W} \text {,app }}^{-1}$ and $Q$ are plotted as a function of $\bar{c}$ according to eqs 8 and 9 , respectively. The numerical data for $M_{\mathrm{W}}, M_{\mathrm{Z}} / M_{\mathrm{W}}$, and $A_{2}$ are presented together with $M_{\mathrm{W}}$ data measured in $m$-cresol in Table I. The values of $A_{2}$ for PET in HFIP were evaluated by the least mean square of eq 8 . The $M_{\mathrm{W}}$ value for the unfrac- 


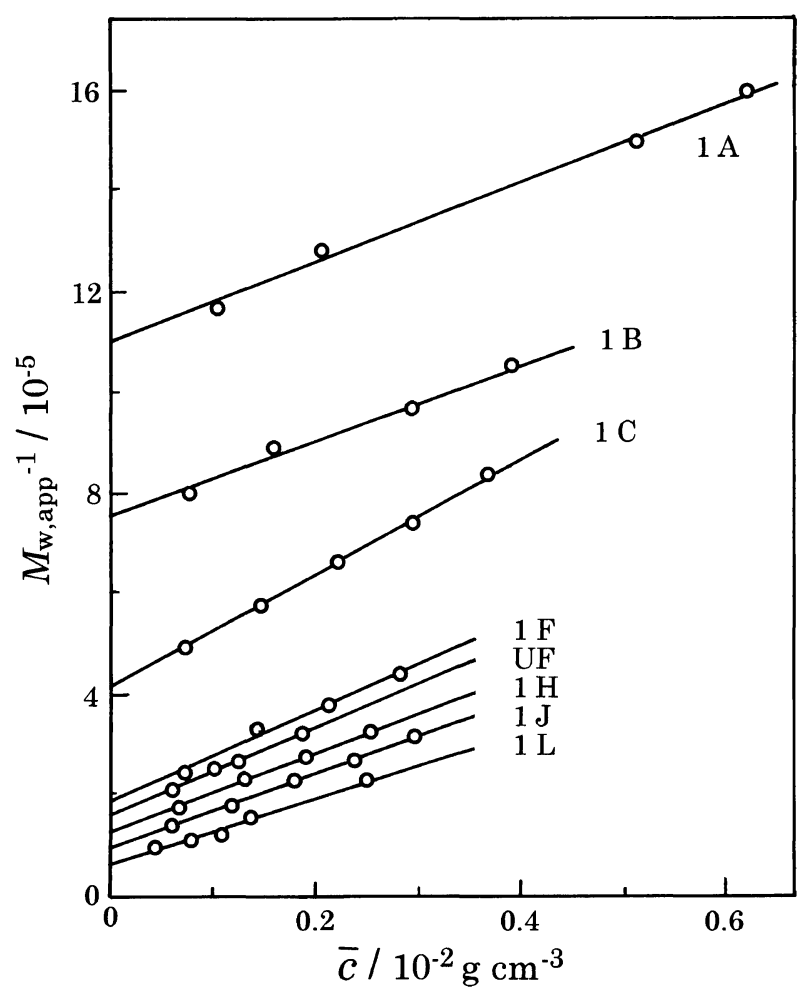

Figure 1. Plots of $M_{\mathrm{W}, \text { app }}^{-1}$ vs. $\bar{c}$ for PET fractions in HFIP at $30^{\circ} \mathrm{C}$.

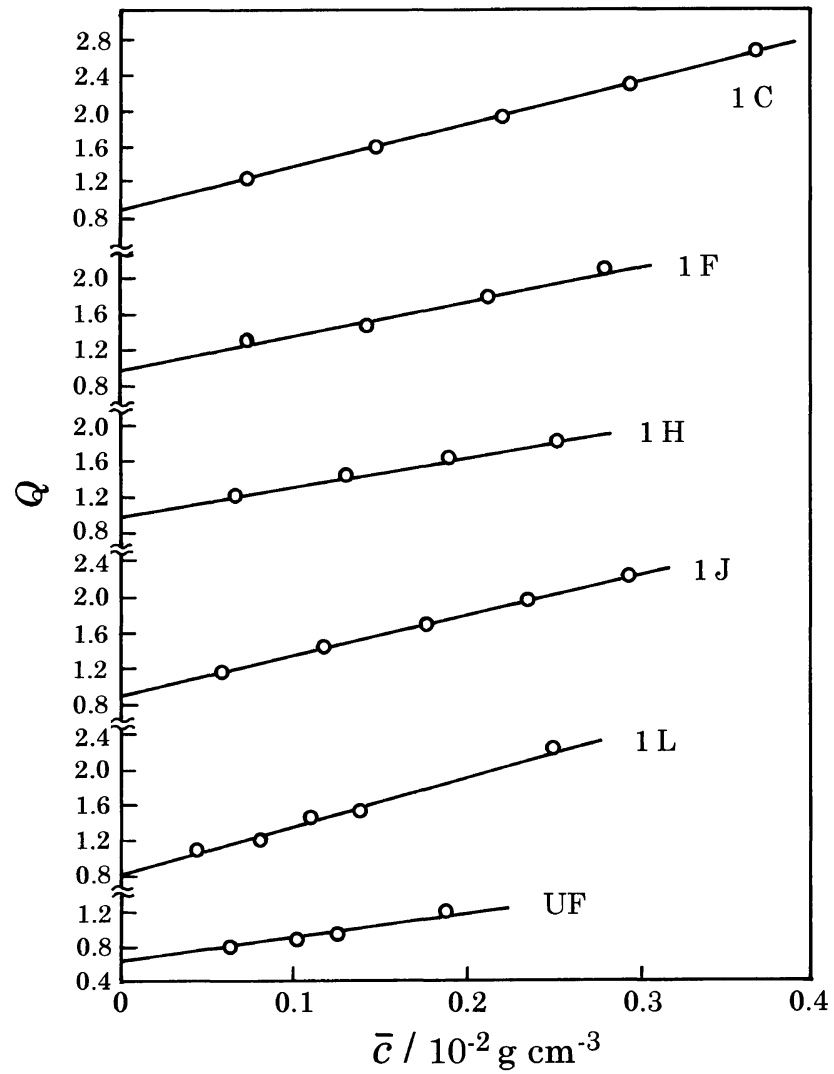

Figure 2. Plots of $Q$ vs. $\bar{c}$ for PET fractions in HFIP at $30^{\circ} \mathrm{C}$.

Table I. Results of sedimentation equilibrium measurement for PET samples in HFIP at $30^{\circ} \mathrm{C}$

\begin{tabular}{|c|c|c|c|c|c|}
\hline Sample & $M_{\mathrm{W}} \times 10^{-4}$ & $\frac{A_{2} \times 10^{4}}{\mathrm{~mol} \mathrm{~g}^{-2} \mathrm{~cm}^{3}}$ & $A_{2} M_{\mathrm{W}} /[\eta]$ & $M_{\mathrm{Z}} \times 10^{-4}$ & $M_{\mathrm{Z}} / M_{\mathrm{W}}$ \\
\hline $\mathrm{UF}^{\mathrm{a}}$ & $\begin{array}{l}6.32 \\
6.36^{\mathrm{b}}\end{array}$ & 43.7 & 244 & 9.92 & 1.57 \\
\hline $1 \mathrm{~A}$ & 0.91 & 39.4 & & & \\
\hline 1B & 1.33 & 47.3 & & & \\
\hline $4 \mathrm{~A}$ & 2.33 & 50.1 & & & \\
\hline $1 \mathrm{C}$ & 2.43 & 56.1 & 229 & 2.77 & 1.11 \\
\hline 1D & $2.93^{\mathrm{b}}$ & & & & \\
\hline $1 F$ & 5.40 & 45.7 & 239 & 5.65 & 1.05 \\
\hline $1 G$ & $6.57^{\mathrm{b}}$ & & & & \\
\hline $1 \mathrm{H}$ & 7.90 & 39.9 & 235 & 8.15 & 1.03 \\
\hline $1 \mathrm{I}$ & $9.68^{\mathrm{b}}$ & & & & \\
\hline $1 \mathrm{~J}$ & 10.6 & 36.1 & 230 & 11.8 & 1.11 \\
\hline $4 \mathrm{E}$ & 11.6 & 35.7 & 233 & 12.8 & 1.10 \\
\hline $1 \mathrm{~K}$ & $13.2^{\mathrm{b}}$ & & & & \\
\hline $1 \mathrm{~L}$ & 16.1 & 32.7 & 230 & 19.9 & 1.23 \\
\hline
\end{tabular}

${ }^{\mathrm{a}}$ Unfractionated sample. ${ }^{\mathrm{b}}$ Measured in $m$-cresol at $30^{\circ} \mathrm{C}$.

tionated sample (UF) obtained in HFIP was in good agreement with that from $m$-cresol solution. From the $M_{\mathrm{Z}} / M_{\mathrm{W}}$ ratios, these fractions are found to have considerably narrow distribution in molecular weight. In view of the experimental accuracy of measurements, data on $A_{2}$ by eq 9 and from $m$-cresol solutions were excluded from the consideration of the dependence on molecular weight and of $A_{2} M /[\eta]$ ratio.

The $A_{2} M_{\mathrm{W}} /[\eta]$ value was 234 on the average for the fractions of molecular weight $>2.4 \times 10^{4}$, being in agreement with the result (225) in TFA by Wallach, ${ }^{1}$ but not with that (100) in the same solvent by Kamada et al. ${ }^{3}$

The long-range interactions between chain elements in dilute solutions are represented by the binary cluster integral,

$$
\beta=\int_{0}^{\infty}\left(1-e^{-U(r) / k T}\right) 4 \pi r^{2} \mathrm{~d} r
$$

where $U(r)$ is the pair potential of average force as a function of the intersegmental distance $r$. The linear expansion factor $\alpha$ can, then, be expressed in terms of the excluded volume parameter $z$ which may be written as

$$
z=\left(4 \pi\left\langle S^{2}\right\rangle_{0}\right)^{-3 / 2} n^{2} \beta
$$


for a chain of $n$ bonds of the bond length $l$, and the chain dimension in solution can be described by the two parameters $A$ and $B$,

$$
A^{2}=\left\langle S^{2}\right\rangle_{0} / 6 M=s l^{2} / m
$$

and

$$
B=\beta / \mathrm{m}^{2}
$$

where $\left\langle S^{2}\right\rangle_{0}$ is the mean square radius of gyration at $T$ $=\Theta, s$ is the skeletal factor, and $m(=M / n)$ is the average molar weight per skeletal carbon atom. Since the second virial coefficient is essentially the problem of the excluded volume effect between two contact chains, $A_{2}$ may also be expressed in terms of the short-range and the long-range interaction parameters, $A$ and $B$. According to the so-called two-parameter theory, Tanaka and Solc ${ }^{24}$ have described $A_{2}$ is a function of $z$ and written as

$$
A_{2}=\frac{N_{\mathrm{A}} \beta}{2 m^{2}} h(z)
$$

with

$$
h(z)=(1+6.856 z)^{-0.418}
$$

where $N_{\mathrm{A}}$ is the Avogadro number. The function $h(z)$ is the only source of the molecular weight dependence of $A_{2}$.

According to the helical wormlike theory, ${ }^{20}$ on the other hand, $A_{2}$ may be written in the form,

$$
A_{2}=4 \pi^{3 / 2} N_{\mathrm{A}}\left(\left\langle S^{2}\right\rangle^{3 / 2} / M^{2}\right) \Psi
$$

where $\Psi$ is the interpenetration function. $A_{2} M /[\eta]$, therefore, can be expressed in terms of the Flory-Fox relation, $\left.{ }^{25}[\eta]=6^{3 / 2} \Phi<S^{2}\right\rangle_{0}^{3 / 2} / M$ ( $\Phi$ : Flory constant) as,

$$
A_{2} M /[\eta]=4 \pi^{3 / 2} N_{\mathrm{A}} \Psi\left(6^{3 / 2} \Phi\right)
$$

Miyaki, et al. ${ }^{17}$ have reported that the value of $\Psi$ is 0.22 for very high molecular weight samples in good solvent (for example, polystyrene of $M_{\mathrm{W}}$ above $8.8 \times 10^{6}$ in benzene), and Einaga, et $a l .{ }^{18}$ has described the $\Phi$ value of $1.8 \times 10^{23}$ for the similar systems. Substituting these values in eq 19, the theoretical upper bound value of $A_{2} M /$ $[\eta]$ ratio may be 110 in the limit of infinite molecular weight in very good solvents. The $A_{2} M_{\mathrm{W}} /[\eta]$ ratios observed in this work, however, are far beyond the upper limit value expected for high polymers. The existence of molecular weight distribution in the fractions and the overestimation of $A_{2}^{22}$ seem to be the reason for high $A_{2} M_{\mathrm{W}} /[\eta]$ value.

The values of $A_{2}$ against molecular weight $M_{\mathrm{W}}$ are plotted double-logarithmically in Figure 3. The molecular weight dependence of $A_{2}$ is obtained as $A_{2}=1.12 \times$ $10^{-1} M_{\mathrm{W}}{ }^{-0.29}$ in HFIP by the least mean square method, and those recalculated from the light scattering data of Wallach ${ }^{1}$ and of Kamada et al. ${ }^{3}$ in TFA are $A_{2}=3.33 \times$ $10^{-2} M_{\mathrm{W}}{ }^{-0.24}$ and $A_{2}=3.45 \times 10^{-2} M_{\mathrm{W}}{ }^{-0.26}$, respectively.

$A_{2}$ is written in the usual emperical form,

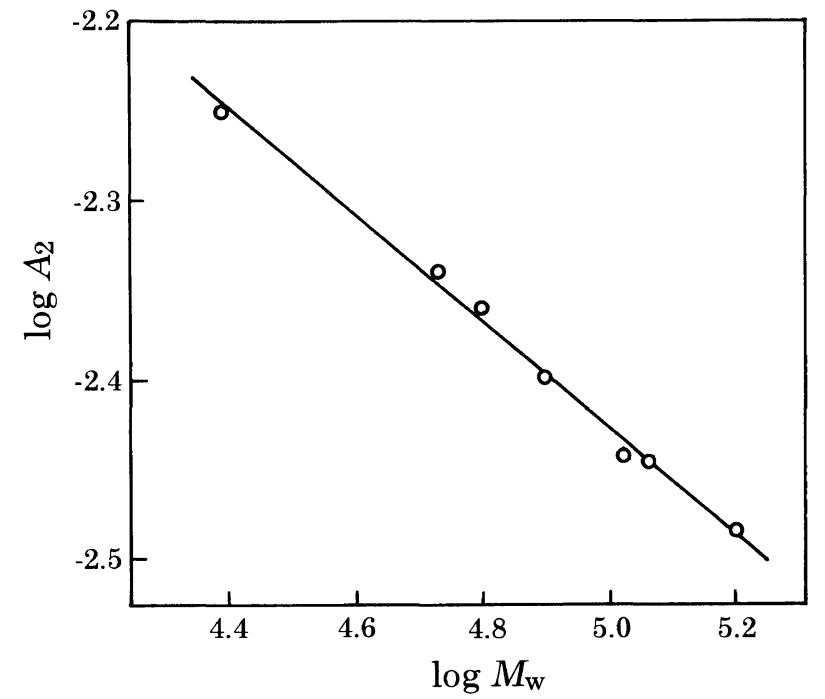

Figure 3. Dependence of second virial coefficient $A_{2}$ on weight average molecular weight for PET in HFIP at $30^{\circ} \mathrm{C}$.

$$
A_{2}=\text { const. } M^{-\gamma}
$$

and the theories indicate that, when $\Psi$ converges a constant value in the limit $(M \rightarrow \infty)$ in good solvents, the largest possible value of an exponent $\gamma$ must be 0.20 . It has been pointed out, ${ }^{19}$ on the other hand, that the theory of $A_{2}$ for flexible polymers should be reconsidered in order to explain the observed inconsistencies with the two-parameter theory prediction. One is the decrease in $\Psi$ with $M$ in good solvents even in ordinary range of $M$. This observation may be interpreted by considering effects of stiffness of chain on $\Psi$ and on the expansion factor $\alpha_{\mathrm{S}}$, according to the helical wormlike chain theory. It has been described also that both effects of chain stiffness and chain ends on $A_{2}$ become significant in the low molecular weight region. ${ }^{16,19}$ The larger values of the exponent $\gamma$ than 0.2 may be attributed to the same influences. The $A_{2}$ values in TFA with light scattering and those in HFIP with sedimentation equilibrium had rather high dependence on molecular weight as shown above.

The numerical results from sedimentation velocity method and viscometry are summarized in Table II, and the double-logarithmic plots of limitting sedimentation coefficient $s_{0}$ vs. $M_{\mathrm{W}}$ in HFIP and $m$-cresol are presented in Figure 4.

The friction constant $f_{0}$ can be related to the sedimentation coefficient $s_{0}$ by

$$
s_{0}=M\left(1-\bar{v} \rho_{0}\right) / N_{\mathrm{A}} f_{0}
$$

where the subscript zeros of $s$ and $f$ refer to infinite dilution. Stockmayer and Albrecht ${ }^{26}$ have given a perturbation calculation of $f_{0}$ for flexible chains with excluded volume as follows:

$$
f_{0} / \eta_{0}=K_{\mathrm{f}} M^{1 / 2} \alpha_{\mathrm{f}}
$$

with

$$
K_{\mathrm{f}}=6^{1 / 2} P\left(\left\langle S^{2}\right\rangle_{0} / M\right)^{1 / 2}
$$


Table II. Hydrodynamic parameters for PET samples in hexafluoroisopropanol and $m$-cresol at $30^{\circ} \mathrm{C}$

\begin{tabular}{|c|c|c|c|c|c|c|}
\hline \multirow{3}{*}{ Sample } & \multicolumn{3}{|c|}{ in hexafluoroisopropanol } & \multicolumn{3}{|c|}{ in $m$-cresol } \\
\hline & {$[\eta]$} & $s_{0}$ & $\Phi^{1 / 3} P^{-1}$ & {$[\eta]$} & $s_{0}$ & $\Phi^{1 / 3} P^{-1}$ \\
\hline & $10^{2} \mathrm{~cm}^{3} \mathrm{~g}^{-1}$ & $\mathrm{~S}$ & $10^{6} \mathrm{~mol}^{-1 / 3}$ & $10^{2} \mathrm{~cm}^{3} \mathrm{~g}^{-1}$ & $\mathrm{~S}$ & $10^{6} \mathrm{~mol}^{-1 / 3}$ \\
\hline $1 \mathrm{~A}$ & 0.407 & -0.264 & $3.81^{\mathrm{a}}$ & & & \\
\hline $1 B$ & 0.475 & -0.311 & $3.68^{\mathrm{a}}$ & & & \\
\hline $4 \mathrm{~A}$ & 0.588 & & & & & \\
\hline $1 \mathrm{C}$ & 0.593 & -0.323 & 2.75 & 0.398 & 0.146 & 2.95 \\
\hline 1D & & & & 0.459 & 0.152 & 2.89 \\
\hline $1 \mathrm{~F}$ & 1.03 & -0.411 & 2.48 & 0.676 & 0.177 & 2.50 \\
\hline UF & 1.13 & -0.476 & 2.65 & 0.731 & & \\
\hline $1 \mathrm{G}$ & & & & 0.792 & 0.206 & 2.51 \\
\hline $1 \mathrm{H}$ & 1.34 & -0.486 & 2.48 & 0.909 & & \\
\hline $1 \mathrm{I}$ & 1.60 & & & & & \\
\hline $1 \mathrm{~J}$ & 1.66 & -0.544 & 2.45 & 1.09 & 0.212 & 2.28 \\
\hline $4 \mathrm{E}$ & 1.77 & & & & 0.224 & \\
\hline $1 \mathrm{~K}$ & & -0.622 & & 1.27 & 0.239 & 2.30 \\
\hline $1 \mathrm{~L}$ & 2.28 & -0.649 & 2.46 & & & \\
\hline Mean & & & 2.54 & & & 2.57 \\
\hline
\end{tabular}

${ }^{a}$ Data for $1 \mathrm{~A}$ and $1 \mathrm{~B}$ were excluded on averaging experimental $\Phi^{1 / 3} P^{-1}$ values.

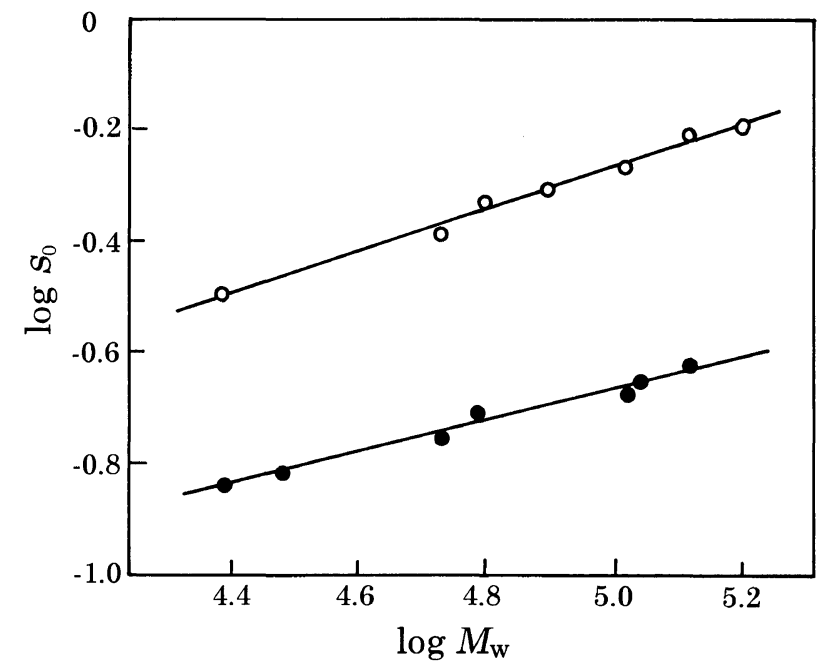

Figure 4. Dependences of limiting sedimentation coefficient $s_{0}$ on weight average molecular weight for PET in HFIP $(\bigcirc)$ and in $m$ $\operatorname{cresol}(\bigcirc)$ at $30^{\circ} \mathrm{C}$.

$$
\alpha_{\mathrm{f}}=1+0.609 z-\cdot \cdot
$$

where $\eta_{0}$ is the solvent viscosity and the theoretical value of $P$ by Kirkwood-Riseman ${ }^{27}$ is 5.11 in the limit of impermeable coil. According to Mandelkern and Flory, ${ }^{28}$ an expression for molecular weight have been yielded with the combination of eq 22 and $[\eta]=[\eta]_{\theta} \alpha_{\eta}^{3}$,

$$
M^{2 / 3}=\frac{s_{0}[\eta]^{1 / 3} \eta_{0} N_{\mathrm{A}}}{\Phi^{1 / 3} P^{-1}\left(\alpha_{\eta} / \alpha_{\mathrm{f}}\right)\left(1-\bar{v} \rho_{0}\right)}
$$

The factor $\alpha_{\eta} / \alpha_{\mathrm{f}}$ is 0.97 in the asymtoic limit of very good solvents. This indicates that the quantity $\Phi^{1 / 3} P^{-1}$ varies in the range of $2.6-2.7 \times 10^{6} \mathrm{~mol}^{-1 / 3} .15 \mathrm{Kirkwood}$ -Riseman ${ }^{27}$ have proposed the $\Phi^{1 / 3} P^{-1}$ value of $2.8 \times$ $10^{6} \mathrm{~mol}^{-1 / 3}$, and Yamakawa ${ }^{20}$ has offered the values of 2.2 to 2.3 for the flexible polymers in $\Theta$ solvents. Flory ${ }^{29}$ has summarized, on the other hand, these quantities observed for several polymer-solvent systems in his text- book and shown that the mean value of them is $2.5 \pm 0.1$ $\times 10^{6}$. As seen in Table II, the values of $\Phi^{1 / 3} P^{-1}$ obtained in this work were, on the average, $2.54 \times 10^{6}$ $\mathrm{mol}^{-1 / 3}$ for PET in HFIP and $2.57 \times 10^{6} \mathrm{~mol}^{-1 / 3}$ in $\mathrm{m}$ cresol. These $\Phi^{1 / 3} P^{-1}$ values are intermediate between those in good and poor solvents predicted by the theories and in excellent agreement with the experimental values as described above.

The Flory's (modified) fifth law ${ }^{30-32}$ predicts that, for large $M$,

$$
\begin{aligned}
& a_{\mathrm{f}}=0.5-0.6 \text { in } f_{0}=K_{\mathrm{f}} M^{\mathrm{a}_{\mathrm{f}}} \\
& a_{\mathrm{S}}=0.4-0.5 \text { in } s_{0}=K_{\mathrm{S}} M^{\mathrm{a}_{\mathrm{s}}}
\end{aligned}
$$

On the other hand, if the small difference between $\alpha$ and $\alpha_{\mathrm{f}}\left(\alpha=0.985 \alpha_{\mathrm{f}}\right)$ is neglected, then

$$
a_{\mathrm{S}}=(2-a) / 3
$$

where $a$ is an exponent in the MHS relation. According to this equation, the $a_{\mathrm{S}}$ value approaches also the lower limit of 0.4 ( $a=0.8$, in very good solvents) and the upper limit of 0.5 ( $a=0.5$, in theta solvents). From the plots in Figure 4, the sedimentation coefficient-molecular weight relationships are found to be

$$
s_{0}=7.11 \times 10^{-3} M_{\mathrm{W}}^{0.38} \text { in HFIP at } 30^{\circ} \mathrm{C}
$$

and

$$
s_{0}=7.07 \times 10^{-3} M_{\mathrm{W}}{ }^{0.30} \text { in } m \text {-cresol at } 30^{\circ} \mathrm{C}
$$

The molecular weight dependences of $s_{0}$, on the other hand, recalculated from the results in $m$-cresol by Meyerhoff and Shimotsuma ${ }^{2}$ are

$$
s_{0}=4.66 \times 10^{-2} M_{\mathrm{SD}}{ }^{0.20} \text { in } m \text {-cresol at } 50^{\circ} \mathrm{C}
$$

and

$$
s_{0}=1.06 \times 10^{-2} M_{\mathrm{SD}}^{0.24} \text { in } m \text {-cresol at } 25^{\circ} \mathrm{C}
$$


where $M_{\mathrm{SD}}$ is an average molecular weight calculated by the Svedberg equation based on sedimentation and diffusion data. The exponents $a_{\mathrm{S}}$ in HFIP (eq A) agrees with those expected in good solvents, while those in $m$ cresol (eqs B-D) are rather smaller than the theoretical lower limit. The discrepancy in the $a_{\mathrm{S}}$-values in eqs B$\mathrm{D}$ appears to attribute to an experimental difficulty in highly viscous solvent, $m$-cresol. Besides, Meyerhoff and Shimotsuma ${ }^{2}$ observed a degradation of PET chains upon dissolution in $m$-cresol, although no decrease in degree of polymerization was found in this work (see Table I).

\section{On the Viscosity Data}

Figure 5 represents the double logarithmic plots of $[\eta]$ against $M_{\mathrm{W}}$ for PET in HFIP and $m$-cresol. The following MHS relations were obtained by means of the least mean square method for these plots,

$$
\begin{aligned}
& {[\eta]=2.95 \times 10^{-4} M_{\mathrm{W}}{ }^{0.72} \text { in HFIP at } 30^{\circ} \mathrm{C}} \\
& \left(3.1 \times 10^{4}<M_{\mathrm{W}}<16.1 \times 10^{4}\right) \\
& {[\eta]=4.97 \times 10^{-3} M_{\mathrm{W}}{ }^{0.48} \text { in HFIP at } 30^{\circ} \mathrm{C}} \\
& \left(0.9 \times 10^{4}<M_{\mathrm{W}}<3.1 \times 10^{4}\right) \\
& {[\eta]=4.04 \times 10^{-4} M_{\mathrm{W}}{ }^{0.68} \text { in } \mathrm{m}-\mathrm{C} \text { at } 30^{\circ} \mathrm{C}} \\
& \left(2.4 \times 10^{4}<M_{\mathrm{W}}<13.2 \times 10^{4}\right)
\end{aligned}
$$

where $m$-C stands for $m$-cresol and $[\eta]$ is expressed in $100 \mathrm{~cm}^{3} \mathrm{~g}^{-1}$. For comparison with our results, the MHS equations recalculated from the values of $[\eta]$ and molecular weight in representative literatures are also shown below;

$$
\begin{aligned}
& {[\eta]=4.24 \times 10^{-4} M_{\mathrm{W}}{ }^{0.72} \text { in TFA at } 30^{\circ} \mathrm{C}} \\
& \left(2.9 \times 10^{4}<M_{\mathrm{W}}<9.5 \times 10^{4}\right)^{3} \\
& {[\eta]=2.49 \times 10^{-3} M_{\mathrm{W}}{ }^{0.55} \text { in TFA at } 30^{\circ} \mathrm{C}} \\
& \left(0.6 \times 10^{4}<M_{\mathrm{W}}<2.9 \times 10^{4}\right)^{3} \\
& {[\eta]=2.37 \times 10^{-4} M_{\mathrm{W}}{ }^{0.68} \text { in TFA at } 30^{\circ} \mathrm{C}} \\
& \begin{aligned}
& \left(2.6 \times 10^{4}<M_{\mathrm{W}}<11.8 \times 10^{4}\right)^{1} \\
{[\eta]=3.48 \times 10^{-4} M_{\mathrm{SD}}{ }^{0.67} } & \text { in m-C at } 25^{\circ} \mathrm{C} \\
& \left(2.3 \times 10^{4}<M_{\mathrm{SD}}<7.7 \times 10^{4}\right)^{2}
\end{aligned}
\end{aligned}
$$

where $M_{\mathrm{W}}$ in eqs $\mathrm{G}$ and $\mathrm{H}$ were determined by the light scattering method and $M_{\mathrm{SD}}$ in eq I by the sedimentationdiffusion method.

The MHS equations for PET in HFIP established in this work (eqs E and E') are virtually identical, over the whole range of molecular weight measured, with those (eqs G and G') recalculated from the data of Kamada et al. in TFA. ${ }^{3}$ The deviations from the linear approximation of eq E for PET in HFIP (Figure 5) and eq G for PET in TFA occur in the ranges of molecular weight below $M_{\mathrm{W}}$ of $3.1 \times 10^{4}$ and $2.9 \times 10^{4}$, respectively. This behavior is consistent with the hydrodynamic theories. ${ }^{25,33,34}$ That is to say, with decreasing the degree of polymerization, the expansion of the polymer molecule due to long-range interaction between its segments would vanish whether it is dissolved in a good solvent or poor solvent. In other words, this is explained by the facts that the molecular dimensions of polymer of very low molecular weight at infinite dilution are independent of the solvent nature and that a pseudo- $\Theta$ state is realized. As the result, the viscosity exponent $a$ decreases with decreasing molecular weight and eventually approaches 0.5 even in good

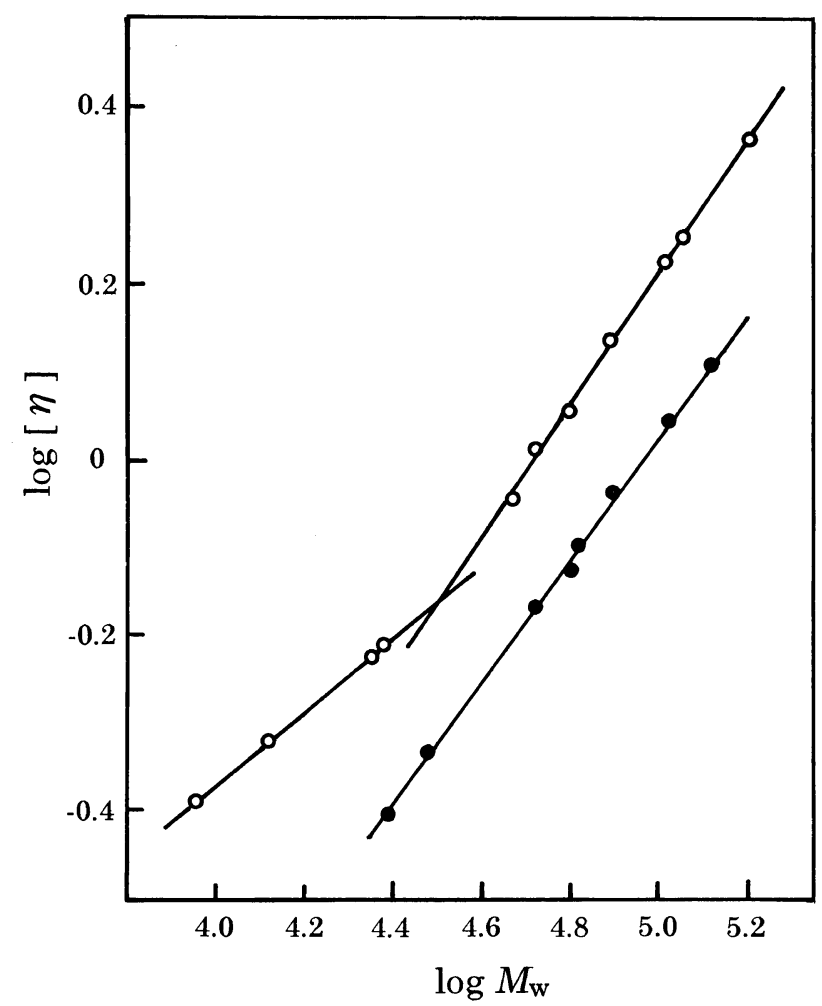

Figure 5. Dependences of intrinsic viscosity $[\eta]$ on weight average molecular weight for PET in $\operatorname{HFIP}(\bigcirc)$ and in $m$-cresol $(\bigcirc)$ at $30^{\circ} \mathrm{C}$.

solvents. The $a$-value in eq E' equals 0.5 approximately, though $K$ ' was considerably larger than the Stockmayer -Fixman constant $K$ (see Table III). The analogous behaviors of MHS plot in the low molecular weight region have been reported for many polymer-solvent systems. $^{35-40}$

The existent distribution of molecular weights in the polymer samples has to be taken into account in quantitative discussions of dilute solution properties. We are here ultimately interested in a fair estimate of the unperturbed chain dimensions of PET by use of the expression,

$$
K=\Phi_{0}\left(\left\langle r^{2}\right\rangle_{0} / M\right)^{3 / 2}
$$

where $\Phi_{0}$ and $\left\langle r^{2}\right\rangle_{0}$ are the viscosity constant and the mean square end to end distance in an ideal state, respectively. The unperturbed dimension $\left(\left\langle r^{2}\right\rangle_{0} / M\right)^{1 / 2} \mathrm{de}-$ pends quantitatively on $K$ and $\Phi_{0}$, and for this reason, the heterogeneity corrections should be required. For the polymers with the Schulz-Zimm distribution, ${ }^{41,42}$ the weight fraction $w_{\mathrm{i}}$ of the molecule $\mathrm{i}$ with molecular weight $M_{\mathrm{i}}$ in the sample is represented by the exponential function,

$$
w_{\mathrm{i}}\left(M_{\mathrm{i}}\right)=\frac{y^{h+1}}{h !} M_{\mathrm{i}}^{h} e^{-y M_{\mathrm{i}}}
$$

with

$$
y=h / M_{\mathrm{n}}=(h+1) / M_{\mathrm{W}}=(h+2) / M_{\mathrm{Z}}
$$


Table III. Unperturbed chain dimensions of PET in various solvents at $30^{\circ} \mathrm{C}$

\begin{tabular}{|c|c|c|c|c|}
\hline \multirow{2}{*}{ Solvent } & $K$ & $\left(\left\langle r^{2}\right\rangle_{0} / M\right)^{1 / 2}$ & $\Phi_{0 \mathrm{w}}{ }^{\mathrm{a}}$ & \multirow[b]{2}{*}{$\sigma$} \\
\hline & $10^{2} \mathrm{~cm}^{3} \mathrm{~g}^{-1}$ & $10^{8} \mathrm{~cm}$ & $10^{-21}$ & \\
\hline Hexafluoroisopropanol & $0.266^{\mathrm{b}}$ & 0.982 & 2.81 & 1.43 \\
\hline \multirow[t]{2}{*}{$m$-Cresol } & $0.189^{b}$ & 0.876 & 2.81 & 1.28 \\
\hline & $0.153^{\mathrm{c} *}$ & 0.817 & 2.8 & 1.21 \\
\hline \multirow[t]{2}{*}{ Trifluoroacetic acid } & $0.214^{\mathrm{d} *}$ & 0.928 & 2.68 & 1.35 \\
\hline & $0.281^{\mathrm{e} *}$ & 1.014 & 2.7 & 1.48 \\
\hline$o$-Chlorophenol & $0.222^{\mathrm{c} *}$ & 0.925 & 2.8 & 1.35 \\
\hline
\end{tabular}

${ }^{\mathrm{a}} \Phi_{0 \mathrm{~W}}=q_{\mathrm{w}} \Phi_{0} ; q_{\mathrm{W}}=0.98$ in this work. ${ }^{\mathrm{b}}$ This work. ${ }^{\mathrm{c}}$ G. Meyerhoff and S. Shimotsuma (at $\left.25^{\circ} \mathrm{C}\right) .{ }^{2}{ }^{\mathrm{d}} \mathrm{M} . \mathrm{L}$. Wallach. ${ }^{1} \quad{ }^{\mathrm{e}} \mathrm{K}$. Kamada $e t$ $a l .{ }^{3}{ }^{\mathrm{f}} \mathrm{K}$. Kamide et al. (at $\left.35^{\circ} \mathrm{C}\right){ }^{4}$ Those with superscripts b, d, and e are the $K$-values after the correction for polydispersity. ${ }^{*}$ Recalculated from the data of $[\eta]$ and $M_{\mathrm{W}}$ in the literatures. ${ }^{1-3}$

where $h$ is constant. Since the MHS relationships have been established by the measurements of $M_{\mathrm{W}}$ in this work, the MHS constant $K$ ' may be denoted here by $K_{\mathrm{W}}$ '. The $[\eta]-M$ relation for the polydisperse sample, therefore, is expressed in terms of $M_{\mathrm{W}}$ as

$$
[\eta]=K_{\mathrm{W}} M_{\mathrm{W}}{ }^{\mathrm{a}}
$$

Since $[\eta]=\sum w_{\mathrm{i}}[\eta]_{\mathrm{i}}$, we obtain

$$
K_{\mathrm{W}}{ }^{\prime}=K^{\prime} \frac{\Gamma(h+1+a)}{(h+1)^{\mathrm{a}} \Gamma(h+1)}
$$

here $\Gamma$ is the gamma function. Then, the $[\eta]-M$ relation for the monodisperse sample can be expressed as hereunder,

$$
[\eta]=K_{\mathrm{W}}{ }^{\prime} q_{\mathrm{W}}^{-1} M^{\mathrm{a}}=K^{\prime} M^{\mathrm{a}}
$$

where $q_{\mathrm{W}}\left(=K_{\mathrm{W}}{ }^{\prime} / K^{\prime}\right)$ refers to the correction factor.,15 The values of $h$ were evaluated for six PET fractions $\left(M_{\mathrm{W}}>3.1 \times 10^{4}\right)$ by using the relation $M_{\mathrm{Z}} / M_{\mathrm{W}}=(h+2) /(h$ $+1)$ in this work. By putting the results $(h \sim 4.9)$ into eq $32, q_{\mathrm{W}}$ was estimated as 0.98 on the average. Thus, the MHS relationship for the monodisperse PET with HFIP at $30^{\circ} \mathrm{C}$ is given as

$$
[\eta]=3.01 \times 10^{-4} M^{0.72}\left(3.1 \times 10^{4}<M_{\mathrm{W}}<16.1 \times 10^{4}\right)
$$

The analogous treatments for the data of Kamada et al. ${ }^{3}$ and Wallach ${ }^{1}$ give the $q_{\mathrm{W}}$ values of 0.94 and 0.93 , respectively, and MHS equations for the monodisperse PET in TFA at $30^{\circ} \mathrm{C}$ were estimated as

$$
[\eta]=4.51 \times 10^{-4} M^{0.72}\left(2.9 \times 10^{4}<M_{\mathrm{W}}<9.5 \times 10^{4}\right)
$$

and

$$
[\eta]=2.55 \times 10^{-4} M^{0.68}\left(2.6 \times 10^{4}<M_{\mathrm{W}}<11.8 \times 10^{4}\right)
$$

In a similar way, $\Phi_{0}$ can be corrected for the polydispersity of samples. The correction factor $q_{\mathrm{w}}\left(=\Phi_{0 \mathrm{~W}} / \Phi_{0}\right)$ is 0.98 , as mentioned above. The value of $q_{\mathrm{W}}$ for $K$, and hence $K$, and for $\Phi_{0}$ is obviously very close to unity and may be ignored for the well-fractionated PET samples (Table I).

HFIP is very good solvent for PET as described above, then the Stockmayer-Fixman relationship ${ }^{14}$ may be util-

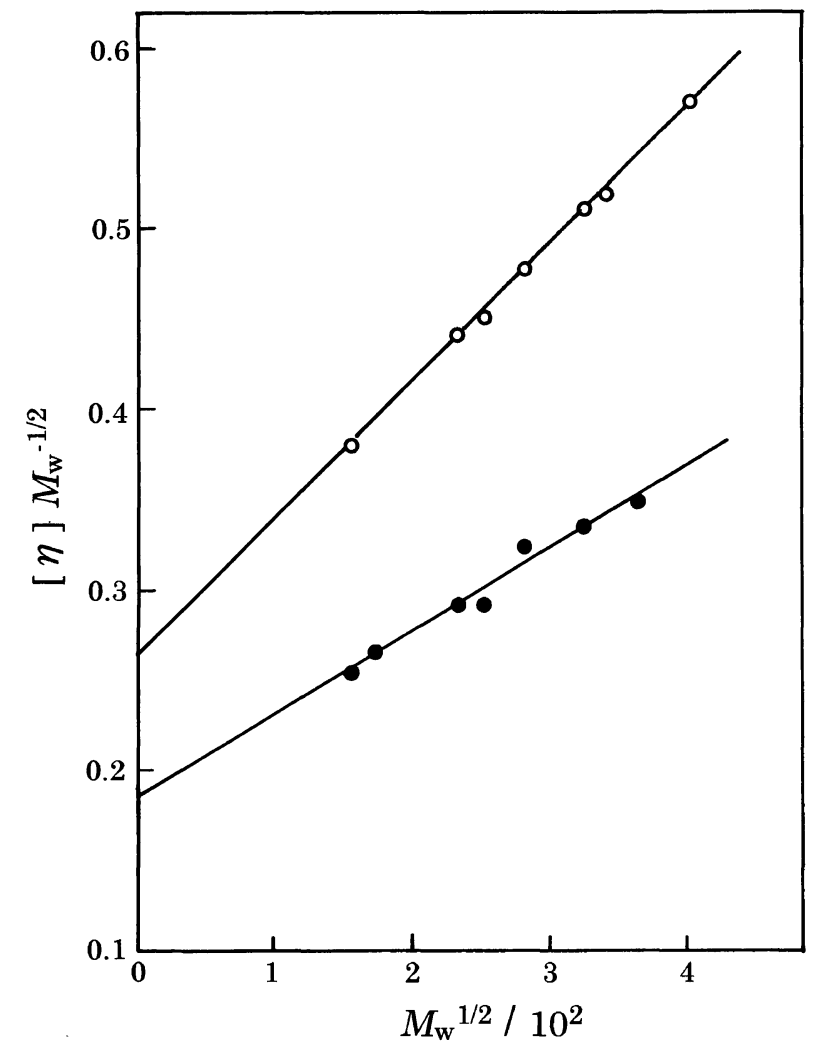

Figure 6. Stockmayer-Fixman plots for PET in HFIP $(\bigcirc)$ and in $m$-cresol (O) at $30^{\circ} \mathrm{C}$.

ized to analyze the short-range interactions in PET chain,

$$
[\eta]=K M^{1 / 2}+0.51 \Phi_{0} B M
$$

where $B$ is the long-range interaction parameter. In Figure 6 are shown the Stockmayer-Fixman plots for PET in HFIP and $m$-cresol. The $K$ vales were determined as the intercept of the plots by the least mean square. The data obtained in this work are listed together with several literature values in Table III. The table includes unperturbed chain dimensions $\left(\left\langle r^{2}\right\rangle_{0} / M\right)^{1 / 2}$ calculated from $K$ values and the steric factors $\sigma\left\{=\left(\left\langle r^{2}\right\rangle_{0}\left\langle r^{2}\right\rangle_{0 \mathrm{f}}\right)^{1 / 2}\right\}$, where $\left\langle r^{2}\right\rangle_{0 \mathrm{f}}$ is the mean square end to end distance for the hypothetical chains with free internal rotation and proposed to be $0.687 \times 10^{-8} \mathrm{~cm}$ for PET. ${ }^{15}$ The $K$ value, and hence $\left(\left\langle r^{2}\right\rangle_{0} / M\right)^{1 / 2}$ varies depending upon the solvent nature and from authors to authors. The $K$ and $\Phi_{0}$ 
values used in calculation of unperturbed dimensions may contain significant error, especially when $M_{\mathrm{n}}$ is employed. Since our results, however, were based on sedimentation equilibrium with the fractionated samples, the influence of polymolecularity on the unperturbed chain dimension can be ignored. The value of $\left(\left\langle r^{2}\right\rangle_{0} /\right.$ $M)^{1 / 2}=0.982 \times 10^{-8} \mathrm{~cm}$ derived from sedimentation equilibrium by the Stockmayer-Fixman extrapolation is in good agreement with the theoretical value of $0.964 \times$ $10^{-8} \mathrm{~cm}$ that Williams and Flory ${ }^{43}$ have estimated using the rotational isomeric model. The values of the unperturbed dimension of PET is still relatively large compared with other addition polymers, ${ }^{15}$ attributing to phenyl group comprised in its chain backbone. The values of chain conformational parameter $\sigma$ for PET range from 1.3 to 1.5 except for one case of 1.21 , irrespective of the solvent nature and author. The mean value of 1.37 for $\sigma$ is relatively low, as it is for other polymers ${ }^{15,44}$ with $p$-phenylene groups in their main chain. PET comprises $\mathrm{C}-\mathrm{O}$ bonds in the chain backbone and has not any side chain, resulting in low steric hindrance against the internal rotation.

\section{CONCLUSIONS}

The narrow distribution fractions of PET over a range in weight average molecular weight from 0.9 to $16 \times 10^{4}$ prepared by a column elution method were investigated by sedimentation velocity and equilibrium, and viscometry in HFIP and $m$-cresol at $30^{\circ} \mathrm{C}$. Some of findings and conclusions obtained in this work may be given below.

The determination of second virial coefficient $A_{2}$ indicates that HFIP, as well as TFA, is very good solvent for PET. $A_{2}$ of PET in HFIP with sedimentation equilibrium give high molecular weight dependence predicted for the helical wormlike chains in very good solvents. The dependences of sedimentation coefficient $s_{0}$ on $M_{\mathrm{W}}$ agree with those expected for good solvents, while those recalculated from the data of Meyerhoff and Shimotsuma ${ }^{2}$ are rather smaller than the theoretical lower limit. The MHS relations established with HFIP as the solvent are virtually identical, over the whole range of $M_{\mathrm{W}}$ measured, with those with TFA by Kamada et al. ${ }^{3}$ The values of the steric factor $\sigma$ evaluated from unperturbed mean square end to end distance range from 1.3 to 1.5 , irrespective of the solvent nature. The small $\sigma$ value for PET suggests that the extent of steric hindrance against the internal rotation of PET chains is very low.

Acknowledgments. The authors are grateful to Prof. K. Kakiuchi (Osaka University) for the kindly and adequate direction on the determination of sedimentation coefficient, Prof. K. Iwata for the helpful suggestions and discussions, and to Mr. S. Hashiya for constructions of light source and detector for the differential refractometer.

\section{REFERENCES}

1. M. L. Wallach, Makromol. Chem., 103, 19 (1967).

2. G. Meyerhoff and S. Shimotsuma, Makromol. Chem., 135, 195 (1970).
3. K. Kamada, T. Hakoda, T. Yoshihara, and K. Nakatsuka, The 19th Polymer Symposium of the Society of Polymer Science, Japan, Kyoto, October 1970, Abstr., p II-625.

4. K. Kamide, Y. Miyazaki, and H. Kobayashi, Polym. J., 9, 317 (1977).

5. S. M. Aharoni, Makromol. Chem., 179, 1867 (1978).

6. Z. Tuzar, V. Vosicky, and M. Bohdanecky, Makromol. Chem., 180, 1399 (1979).

7. V. N. Tsvetkov, L. N. Andreeva, P. N. Lavrenko, and E. V. Beliaeva, Eur. Polym. J., 20, 817 (1984).

8. R. Po', E. Tampellini, E. Occhiello, and F. Garbassi, Polym. Bull, Berlin, 30, 551 (1993).

9. M. Kurata and Y. Tsunashima, in "Polymer Handbook", 4th ed, J. Brandrup, E. H. Immergut, and E. A. Grulke, Ed., John Wiley \& Sons, Inc., New York, N. Y., 1999, p VII-1.

10. M. Naoki, IL-H. Park, S. L. Wunder, and B. Chu, J. Polym. Sci., Polym. Phys. Ed., 23, 2567 (1985).

11. S. Ohoya and T. Matsuo, Chem. Express, 4, 221 (1989).

12. S. Ohoya and T. Matsuo, Chem. Express, 4, 761 (1989).

13. T. Matsuo, M. Sakata, S, Iima, and S. Ohoya, Bull. Res. Inst. Mater. Sci. Eng., Fukui Univ., 21, 55 (1983).

14. W. H. Stockmayer and M. Fixman, J. Polym. Sci., C-1, 137 (1963).

15. M. Kurata and W. H. Stockmayer, Fortschr. Hochpolym.Forsch., 3, 196 (1963).

16. H. Yamakawa, "Helical Wormlike Chains in Polymer Solutions”, Springer-Verlag, Berlin, Heidelberg, 1997, p 272.

17. Y. Miyaki, Y. Einaga, and H. Fujita, Macromolecules, 11, 1180 (1978).

18. Y. Einaga, Y. Miyaki, and H. Fujita, J. Polym. Sci., Polym. Phys. Ed., 17, 2103 (1979).

19. H. Yamakawa, Macromolecules, 25, 1912 (1992).

20. H. Yamakawa, Polym. J., 31, 109 (1999).

21. S. Hashiya, Bull. Technol. Center, Fukui Univ., 4, 37 (1998).

22. H. Fujita, "Foundations of Ultracentrifugal Analysis", WileyInterscience, New York, N.Y., 1975.

23. A. Tsuboi, M. Yamasaki, T. Norisuye, and A. Teramoto, Polym. J., 27, 1219 (1995).

24. G. Tanaka and K. Solc, Macromolecules, 15, 791 (1982).

25. P. J. Flory and T. G. Fox, Jr., J. Am. Chem. Soc., 73, 1904 (1951).

26. W. H. Stockmayer and A. C. Albrecht, J. Polym. Sci., 32, 215 (1958).

27. J. G. Kirkwood and J. Riseman, J. Chem. Phys., 16, 565 (1948).

28. L. Mandelkern and P. J. Flory, J. Chem. Phys., 20, 212 (1952).

29. P. J. Flory, "Principles of Polymer Chemistry", Cornell Univ. Press, Ithaca, N.Y., 1953.

30. P. J. Flory, J. Chem. Phys., 17, 303 (1949).

31. W. H. Stockmayer, Makromol. Chem., 35, 54 (1959).

32. H. Fujita, K. Okita, and T. Norisuye, J. Chem. Phys., 47, 2723 (1967).

33. M. Kurata, W. H. Stockmayer, and A. Roig, J. Chem. Phys., 33, 151 (1960).

34. M. Fixman, J. Chem. Phys., 36, 3123 (1962).

35. C. Rossi, U. Bianchi, and E. Bianchi, Makromol. Chem., 41 31 (1960).

36. T. G. Fox, J. B. Kinsinger, H. F. Mason, and E. M. Schule, Polymer, 3, 71 (1962).

37. R. Okada, Y. Toyoshima, and H. Fujita, Makromol. Chem., 59, 137 (1963).

38. T. Altales, Jr., D. P. Wyman, and V. R. Alex, J. Polym. Sci., A, 2, 4533 (1964).

39. C. Rossi and C. Cuniberti, J. Polym. Sci., B, 2, 681 (1964).

40. S. Arichi, M. Y. Pedram, and J. M. G. Cowie, Eur. Polym. J., 15, 113 (1979).

41. G. V. Schulz, Z. Phys. Chem ., B 43, 25 (1939).

42. B. H. Zimm, J. Chem. Phys., 16, 1099 (1948).

43. A. D. Williams and P. J. Flory, J. Polym. Sci., A-2, 5, 417 (1967).

44. G. V. Schulz and A. Horbach, Makromol. Chem., 29, 93 (1959). 